\title{
Repensar a função docente e desenvolver práticas colaborativas na escola: contribuiçoes da internet
}

\section{Rethinking teaching activity and the development of collaborative practices at school}

Carolina Brandão Gonçalves*

Evandro Ghedin ${ }^{* *}$

\begin{abstract}
Resumo: Neste artigo, apresentamos resumidamente uma experiência em e-learning em que desenvolvemos uma Comunidade de Aprendizagem na Web que reuniu os diferentes formadores de professores do Curso Normal Superio/PROFORMAR, cujo suporte digital utilizado foi a plataforma moodle. Por ocasião da pesquisa foi possível perceber os limites e as perspectivas da educação a distância no Amazonas. Os pressupostos teóricos que orientaram a realização deste projeto identificam-se com os estudos sobre a Formação Continuada de Professores a partir de uma perspectiva critica e emancipadora. Tomamos como base os estudos relativos às novas exigências ao oficio de ensinar, em especial os que indicam a necessidade de repensarmos a função docente e desenvolvermos práticas colaborativas na escola utilizando os recursos da tecnologia. Assim, iniciamos a discussão levantando questões que consideramos relevantes antes de envidarmos qualquer esforço nesse sentido. Em seguida, expomos os factores que condicionam a mudança do nosso fazer profissional, buscando evidenciar as demandas solicitadas ao exercício do magistério, suas condicionalidades, para finalmente relatarmos a experiência vivida na realização do projeto.
\end{abstract}

Palavras chave: Comunidade. Aprendizagem. Formação. Professor.

Abstract: This article presents an e-learning experience in which a Web based learning community has been developed to gather several teacher educators of the course Normal Superior/PROFORMAR, with the digital support of the Moodle platform. During the research process it was possible to understand the restrictions and the perspectives of distance education in the state of Amazonas. The theoretical guidelines of this project are in line with the studies on Teachers Continuing Education, but with a critical and emancipating perspective. The studies relative to the new demands of the teaching activity were the starting point of the study, particularly those that stated the need to rethink the teaching activity and the development of collaborative practices at school using technological resources. Thus, the discussion started by raising relevant questions. Following this, all the issues that can condition adjustments in our profession are presented, seeking to show the demands requested by the office of teaching as well as their obstacles. Finally, the experiences obtained with the development of the project are discussed.

Keywords: Communities. Learning. Training. Teacher.

\footnotetext{
* Doutora em Tecnologia Educativa pela Universidade do Minho.E-mail: krolina_2@hotmail.com

** Professor do Programa de Mestrado em Educação em Ciências da Universidade do Estado do Amazona e no Programa de Doutorado em Educação da UFAM. E-mail: ghedin@usp.br
} 


\section{Introdução}

As abordagens apresentadas neste artigo orientaram um estudo de caso - " $O$ desenvolvimento de Comunidades de Aprendizagem na Formação Continuada de Formadores de Professores" - constituído por professores que atuaram no Curso Normal Superior inseridos no Programa Formação e Valorização do Magistério (PROFORMAR) da Universidade do Estado do Amazonas, que atingiu um universo de dez mil professores dos 62 municípios do Estado.

Segundo André (1986), Ghedin e Franco (2011), os estudos de caso se caracterizam por buscar a descoberta de novos elementos sobre uma dada situação, procuram representar os diferentes e às vezes conflitantes pontos de vista, enfatizam a interpretação em contexto, usam variadas fontes de informação, valorizam a experiência do autor em relação ao assunto estudado e, em comparação a outros relatórios, utilizam uma linguagem mais acessível.

Nossa tentativa foi criar, a partir de uma Comunidade de Aprendizagem na Web, um espaço de discussão, estudo e troca de conhecimentos entres os diferentes formadores do curso (PROFORMAR), de modo a estabelecer uma cultura colaborativa.

Para suportar as situações de ensino e as aprendizagens da formação escolhemos a plataforma vitual de aprendizagem moodle, um site gratuito que permite o desenvolvimento de cursos pela Web, além do resguardo da informação e o tratamento de dados quantitativos por meio de ferramentas de estatística que contabilizam o número de entradas no ambiente, a quantidade de interação, entre outros aspectos. Basicamente o curso compreendeu três momentos fundamentais.

O primeiro momento foi destinado a reunir os sujeitos convidados a participar da formação on-line, especificamente três professores titulares $^{1}$ e 25 assistentes $^{2}$ que atuavam no Curso Normal Superior do PROFORMAR, além do gerenciador da plataforma e um coordenador pedagógico, no caso representado pela figura do pesquisador. Nessa primeira etapa solicitouse aos professores titulares que preparassem o material didático que poderia ser utilizado na web - textos, imagens, sons capazes de sucitar reflexões sobre a prática pedagógica desenvolvida por eles e estabelecer a interação com os assistentes.

No segundo momento realizou-se a operacionalização da Comunidade de Aprendizagem: inscrição dos participantes na plataforma do curso, registro de seus emails, identificações por fotos e inicio da formação on-line, que teve duração de 50 dias aproximadamente, sendo avaliada durante todo o processo.

Uma vez concluído o curso on-line, no terceiro momento, já em etapa presencial, acompanhamos as aulas dos professores assistentes, mediadas pelas tecnologias, a fim de perceber o rendimento da aprendizagem obtida na formação on-line.

\footnotetext{
${ }^{1}$ Na lógica daquele programa de formação, o Professor Titular era o docente da Universidade que ministrava aulas a partir do estúdio que as transmitia para os locais onde estavam os cursistas, na ocasião 158 locais diferentes do Estado do Amazonas.

${ }^{2}$ O Professor Assistente era o docente que estava na sala de aula em cada uma das 158 turmas existentes naquele momento do curso e que se responsabilizava por acompanhar as atividades pedagógicas do curso in loco.
} 


\section{Necessidade de repensar a função docente e desenvolver culturas colaborativas}

Ao falarmos de cultura escolar estamos nos referindo a hábitos, valores, pensamentos, normas e processos que dão sentido à escola enquanto instituição formadora. $\mathrm{O}$ conjunto desses hábitos são traduzidos na forma como a escola organiza seu espaço, estabelece seus horários, define seu currículo, sua prática pedagógica, relaciona-se com seus membros, bem como concebe o conhecimento e define a sua identidade.

Sendo a escola uma instituição situada no tempo e no espaço, influenciada, portanto, pelo contexto histórico e social do qual faz parte, é no mínimo redutor falarmos de "cultura escolar" no singular, pretendendo uma padronização do fenômeno. Antes o que se percebe é a coexistência de múltiplas e complexas formas de agir e pensá-la, que variam entre os continentes, regiões e até localidade. "Não se poderá, portanto, esquecer que, face a uma cultura escolar global de tendência homogeneizante, deve também ser considerada uma realidade local e particular diversa, que frequentemente intervém activamente sobre as orientações e directrizes provenientes do nível macro" (CARVALHO, 2006, p. 7).

Ao longo dos séculos, e de acordo com a sociedade em que esteve inserida, a escola foi assumindo funções e papéis diversos, que foram definindo sua identidade enquanto instituição social. Ao repassar os conhecimentos históricos e socialmente acumulados, visando à preparação do ser humano para a vida em sociedade, a escola foi estabelecendo sua cultura. Assim, como protagonista do processo de socialização humana, a escola é interlocutora de amplos e diversificados discursos sustentados por filosofias nem sempre coincidentes, que justificam/encobrem, direta ou indiretamente, interesses de classes.

Quanto à socialização que se dá na escola, Sacristan (1998) compreende-a como um processo complexo e sutil, influenciado por profundas contradições e inevitáveis resistências individuais. Segundo Tardif (2005), a escola é um espaço em que atuam diversos indivíduos, abrigando tensões, colaboração, conflitos e reajustamentos de suas relações. As concepções de mundo e sociedade constituem a essência da cultura escolar, e será a partir da forma como esta instituição as concebe que o professor orientará a sua prática pedagógica.

Durante muito tempo, o conhecimento cientifico foi visto como uma verdade imutável e absoluta que deveria ser transmitida aos estudantes, bastando a eles memorizar as informações fornecidas pelo professor para que lhes fossem garantidas melhores chances de conviver em sociedade. No entanto, com o desenvolvimento da ciência, em comunhão com o advento da tecnologia, a velocidade com que são produzidas novas informações e vinculadas à mídia, o conhecimento assume sua relatividade, pondo em contestação muitos dos hábitos e valores da antiga escola, exigindo uma nova identidade e o repensar de seus fins e mecanismos de funcionamento. Nesse sentido, para Dias (2004, p. 22),

As tecnologias estão a mudar o modo como os alunos aprendem e também o que podem aprender. Por outro lado, a possibilidade de as tecnologias constituírem um catalisador para a mudança depende não só da democratização do acesso à rede mas também, e de forma muito significativa, das representações que a escola desenvolve sobre elas, enquanto tecnologias da informação e do conhecimento. 
Nasce um consenso, a escola necessita incorporar as tecnologias da informática às sua práticas. "Hoje já não há mais dúvidas de que essas tecnologias devem fazer parte dos processos de aprender. Resta descobrir formas inovadoras de como utilizá-las” (MAGDALENA, 2003, p. 97). Se considerarmos que num país como o Brasil, com contradições sociais históricas, poucas são as pessoas que dispõem dos meios materiais para adquirir um computador, a realização desse ideal passa a ser um desafio do Estado e deve ser incluído como parte das prioridades de suas politicas públicas.

Ao mesmo tempo em que cresce a consciência da importância de se utilizar os recursos tecnológicos nos processos de ensino-aprendizagem para a promoção do ser humano na contemporaneidade, surge o conflito entre o velho e o atual paradigma educativo, com consequências sobre a concepção da cultura escolar.

Muitas vezes, a escola se encontra perdida frente às exigências que lhe são feitas. Se antes o importante era o acúmulo de conhecimento, o que se conseguia com a transmissão da informação, o apelo à memória, com poucas exigências na interacção entre os estudantes, hoje dá-se enfase à criatividade, à autonomia do estudante em construir sua própria trajetória de aprendizagem. "Nações como o Japão estão reduzindo a quantidade de conteúdo prescrito no currículo, promovendo mais flexibilidade dos professores e exigindo mais criatividade em sala de aula” (HARGREAVES, 2004, p. 36).

$\mathrm{O}$ desenvolvimento das pesquisas em educação indica a necessidade de o estudante tornar-se capaz de criar, pensar criticamente, ter autonomia intelectual, utilizar seus arquivos mentais estabelecendo relações com as novas informações e ser capaz de produzir conhecimento, aplicando-o na solução de problemas, dividindo com os outros suas descobertas, ampliando ainda mais a capacidade de criar mediante um processo de construção de saberes em que eles próprios sintam-se partícipes dessas construções e não receptores passivos de um conhecimento acumulado e competentemente transmitido pela escola.

No entanto, os objectivos pretendidos apontam para a necessidade de repensarmos a prática pedagógica em vista a uma transformação da cultura escolar, no modo como o ensino e a aprendizagem são percebidos e operados. Isso causa, de certa forma, algum desconforto, pois muitas vezes não sabemos como e por onde iniciá-la. Temos novos instrumentos, mas não sabemos usá-los. Essa é uma dificuldade aprofundada principalmente quando nosso sistema de representações não consegue estabelecer relações com outras maneiras do fazer pedagógico: “[...] quando nos damos conta de que é preciso construir novas idéias, competências e relações” (MAGDALENA, 2003, p. 23).

A Tecnologia Educativa surge nesse contexto e tem por finalidade repensar a relação entre a sociedade e a prática pedagógica, para estudar a adequação dos recursos tecnológicos ao ambiente de comunicação, além de repensar a função docente com vistas a mantê-la atual e socialmente inclusiva.

Se tomarmos a literatura atual sobre a prática docente, encontraremos um número consideravelmente grande de recomendações ou demandas a serem incorporadas à práxis do professor, tais como: romper o isolamento entre as disciplinas, trabalhar cooperativamente, incorporar novos instrumentos de ensino. Muitas vezes, esse número parece extrapolar o limite do possível realizável e a consequência disso é o desânimo; mas, ao contrário de, mecanicamente, adotar uma ou outra postura, é importante que o professor 
desenvolva o hábito de refletir sistematicamente sobre/na e para a prática que realiza. Desse modo, evita os modismos, desmascara as ideologias, reforça suas certezas e aumenta suas chances de acertos em vistas a perspectivas de mudanças significativas no oficio de ensinar. Ghedin (2002, p. 133) adverte: "Não se trata de pensar um fato, mas revolucioná-lo; os produtos da consciência têm que se materializar para que a transformação ideal penetre no próprio fato”.

Nesse sentido, também são relevantes os trabalhos sobre a profissionalidade docente e a questão da autonomia e dos valores necessários ao exercício do magistério. Contreras (2003), ao analisar a lógica da racionalidade técnica na educação e suas consequências para o processo de proletarização do educador, demonstra que o oficio de ensinar pressupõe o desenvolvimento de princípios como a ética, a moralidade, a competência profissional e o compromisso para com a comunidade. Essas, para o referido autor, são as dimensões fundamentais que determinam a função docente e pelas quais o professor deve defender a importância de sua autonomia profissional.

Segundo Contreras (2003), o ensino estabelece um compromisso moral para quem o realiza, uma vez que o professor utiliza-se da confiança que lhe é conferida pela sociedade para preparar as gerações.

Inevitavelmente, o fato de que o oficio de ensinar consiste na relação direta e continuada com pessoas concretas sobre as quais se pretende exercer uma influência faz com que o docente se encontre comprometido com a legitimidade da referida influência, com a bondade das pretensões e com os aspectos mais pessoais da evolução, os sentimentos e o cuidado e a atenção que podem requerer com as pessoas (NODDINGS, 1986 apud CONTRERAS, 2003, p. 49).
Mesmo que as exigências feitas ao desenvolvimento de atitudes e valores a serem assumidos pela função docente nos pareçam exceder os limites do possível praticável, percebemos algumas urgências que deveriam ser, atenciosamente, consideradas pelo bom senso reflexivo:

- Necessidade de romper com o isolamento entre as ciências, trabalhando cooperativamente em sentido de interdisciplinar saberes, para em seguida ajudar os estudantes a operar do mesmo modo.

- Desenvolvimento das múltiplas inteligências.

- Parceria com a comunidade, pais, responsáveis e instituições interessadas pelos problemas da escola.

- Capacidade de lidar e de oferecer respostas eficazes a situações complexas e de risco.

- Gerenciamento de sua própria formação em vista ao desenvolvimento profissional a partir da participação em Comunidades de Aprendizagem que estimulem a criação de culturas colaborativas em oposição às culturas competitivas.

A perspectiva interdisciplinar na educação vai além da justaposição de diferentes disciplinas trabalhadas por uma equipe de professores sobre um determinado tema ou conteúdo, pois visa superar a fragmentação entre as diferentes áreas do conhecimento, bem como desenvolver no estudante uma compreensão multidisciplinar do mundo e de si próprio. "Podemos dizer que o conhecimento progride não tanto por sofisticação, formalização e abstração, mas principalmente pela capacidade de englobar e contextualizar” (MORIN, 2000, p. 24). 
Os estudos de Fazenda (1998, p. 119) sobre a realização da interdisciplinaridade no ensino brasileiro indicam a proliferação indiscriminada de práticas intuitivas em que o termo tem sido utilizado como slogan, sem que os professores estejam realmente engajados nesse processo. Embora a autora defenda a perspectiva interdisciplinar, chama a nossa a atenção para alguns problemas que têm acontecido no desenvolvimento dessa proposta: "Em nome da interdisciplinaridade, rotinas estabelecidas são condenadas e abandonadas, e slogans, apelidos e hipóteses de trabalho são criados e, muitas vezes, são improvisados e mal elaborados”.

Trabalhar em equipe requer a habilidade de conciliar interesses, ideias, altruísmo, atitudes difíceis na sociedade contemporânea. Por isso, constitui-se de importância especifica para se desenvolver as múltiplas inteligências, especialmente a emocional. Assim, a escola pode transformar-se num espaço de qualificação permanente, sofisticada e capaz de favorecer a aprendizagem constante de seus professores, sendo necessário o trabalho colectivo em torno da realização de pesquisas, busca de soluções de problemas junto a colegas ou em comunidades de aprendizagem profissional.

A parceria com os pais, valorizando-os como parte importante para a formação de seus filhos, e a mobilização dos conhecimentos exteriores de modo a tornar significativo o processo de aprendizado em sala de aula são outra importantes habilidades a serem desenvolvidas pelos docentes em suas práticas pedagógicas.

Hoje vivemos em um mundo interligado de tal forma que, independentemente de onde estejamos, o que acontece em diferentes partes do planeta nos afeta, desestabiliza-nos. Por isso, precisamos aprender a desenvolver, em nós e em nossos estudantes, a disposição para o risco, para lidar com mudanças. No ensino, esses riscos podem ser traduzidos na necessidade de confiarmos nas pessoas que não convivem conosco, compondo, com elas, ações recíprocas que visem à aprendizagem.

Se os professores quiserem fazer progressos como profissionais e causar impacto no mundo complexo das escolas, devem aprender a confiar e valorizar os colegas distantes e diferentes, bem como os semelhante (HARGREAVES, 2004, p. 44).

Nota-se que muitas são as demandas para o ensino e, consequentemente, para a prática atual dos professores. Demandas que precisam ser observadas e refletidas em suas diferentes dimensões: políticas, econômicas e sociais, visando ao desenvolvimento da nova cultura escolar que se desenha em nossa época e que nos mostra perspectivas diversificadas para o processo de ensino e aprendizagem.

Fundamentalmente, ser professor hoje é estar a par das transformações que o mundo vive, comprometer-se com a inclusão social de seus estudantes, adotando rigorosidade cientifica, mobilização de saberes por meio de trabalho interdisciplinar com pessoas diferentes e não necessariamente colegas, parceria com as famílias dos estudantes, coragem para arriscar, inovar, desenvolver o sentimento de responsabilidade social, justiça e solidariedade, a partir de atividades colaborativas. É preciso fazer ver a necessidade da escola, no entanto isso não se faz exclusivamente ao nivel do discurso, mas com trabalho pedagógico fundamentado e eficiente, que responda às expectativas do contexto social e dos valores humanos que se espera dos docentes. 


\section{A Web e o desenvolvimento de uma cultura colaborativa na formação de professores no Amazonas}

Pelas transformações que o mundo vem sofrendo já se pode perceber a necessidade de mudança no processo de ensino e se começa a escrever uma nova forma de pensar e agir na educação. Apesar disso, ainda há muita incerteza no modo como podemos atingir o que pretendemos. Assim, não é por acaso que crescem as iniciativas na formação continua de professores. Entretanto, apesar dos investimentos no desenvolvimento profissional do professor, na ressignificação dos processos pedagógicos, a escola tem incorporado acanhadamente os novos pressupostos epistemológicos que atendem às necessidades de uma educação para este século.

O desenvolvimento de uma cultura colaborativa na escola ganha força com o aparecimento dos espaços emergentes de Educação online, caracterizados pelas comunidades virtuais de aprendizagem, porém estas exigem disponibilidade para interação, troca de experiência e compromisso mútuo para atingir os objetivos de ensino.

O potencial da Internet em favorecer o desenvolvimento de comunidades virtuais tem sido utilizado pela Educação para criar, no ciberespaço, ambientes colaborativos de aprendizagem. Neles, estudantes e professores transpõem as limitações de tempo e espaço e aprendem online. Nessa questão faz-se necessario afirmar, com Bergson (2006), que tempo-espaço passa a ser tempo-movimento, isto é, o tempo de aprendizagem se dá no movimento do hiperespaço e a máquina é a mediação que possibilita a integração entre diferentes espaços-tempos. As relações que se estabelecem não são territorializadas hegemonicamente, mas se configuram a partir das mútuas trocas de informação, tendo em vista o conhecimento do qual cada integrante é autor, condição de sua própria autonomia.

De acordo com Dias (2001, p. 27), “a formação de uma comunidade de aprendizagem compreende a criação de uma cultura de participação coletiva nas interacções que suportam as actividades de aprendizagem dos seus membros". Esses processos de construção da representação do grupo podem ser criados por meio dos mais diferentes espaços na web, nomeadamente blogs, sites de encontro como orkut, fóruns e em plataformas próprias para situações de formação, a qual nesta pesquisa foi realizada no ambiente moodle.

Gonçalves (2010, p. 157) observa que a criação de cursos online tem conseguido reunir um número expressivo de pessoas, contudo nem todos esses grupos podem ser considerados comunidades virtuais de aprendizagem.

Esta compreende um processo bem mais complexo, sustentado em teorias da aprendizagem que proporcionam a compreensão de princípios epistemológicos que favorecem a formação de grupos coesos, envolvidos em práticas colaborativas, articulados em rede.

Os princípios teóricos que têm embasado a formação das comunidades virtuais de aprendizagem reconhecem-se no construtivismo de Piaget (1986; 2007; 2010; 2011) e no interacionismo simbólico de Vigotsky (1998; 1998a; 1998b; 2001). Essas duas perspectivas compreendem a construção do conhecimento como um processo dinâmico em que os estudantes aprendem por conta de suas experiências diretas com os conteúdos de ensino, com os recursos de aprendizagens e pelas interações sociais que estabelecem com seus próprios colegas de curso e professores. 
As comunidades virtuais de aprendizagem reunem pessoas diferentes em torno de interesses e objetivos comuns, a fim de que reflitam, juntas, e encontrem soluções para os problemas em que estejam envolvidas. Nesse sentido, elas se assemelham às comunidades de práticas. Wenger (2001) é um dos estudiosos que se destacam nesse terreno. Segundo ele, as comunidades de prática exigem compromisso mútuo, disponibilidade para negociar interesses e a construção de um repertório comum. Do mesmo modo, as comunidades virtuais de aprendizagem não sobrevivem sem esses pressupostos.

Dessa maneira, para fazer parte de uma comunidade virtual é necessário, antes de qualquer coisa, estar disposto a pertencer a um grupo, negociar interesses pessoais em favor da coletividade, estabelecer regras de convivência em função de objetivos comuns que possam ser partilhados por todos. Salmon (2004) elaborou um modelo baseado em cinco ideias-chave ou etapas que devem ajudar a pensar no desenho para a criação de comunidades virtuais de aprendizagem:

\section{Primeira chave - Acesso e motiva-} ção: Salmon (2004), considera essencial o acesso fácil e regular online, e a autoconfiança do estudante para se manter motivado a permanecer no curso.

Segunda chave - Socialização online: o estabelecimento de laços, o sentimento de pertença é fundamental para a construção do capital simbólico da comunidade virtual de aprendizagem.

\section{Terceira chave - Troca de informa-} ção: a interação ativa entre os membros em torno dos conteúdos disponíveis permite que aprendam uns com os outros.

Quarta chave - Construção do conhecimento: nesta etapa os estudantes adquirem maior autonomia, estão mais prepara- dos para inovar, criar alternativas e soluções para problemas complexos nas e-atividades.

Quinta-chave - Desenvolvimento: na última etapa as habilidades meta-congnitivas dos estudantes estão mais consolidadas e eles dominam as regras de relacionamento que lhes permitem aprender na comunidade virtual de aprendizagem. Também costumam ser mais críticos e apresentam maior autonomia.

O reconhecimento do potencial da Internet na criação de comunidades virtuais e aprendizagem nos impulsionou a realizar, em 2006, um estudo onde pudéssemos observar os limites e as perspectivas do desenvolvimento dessas comunidades no curso de graduação para o magistério desenvolvido pela Universidade do Estado do Amazonas, chamado de PROFORMAR ${ }^{3}$.

No PROFORMAR, os professores-alunos eram preparados por outros professores, cuja exigência era a de já possuírem o diploma de nível superior e pós-graduação, Esses professores dividiam-se nas categorias de: Titulares, Assistentes e Auxiliares. O curso em carácter mediado pela tecnologia possuia um serviço de atendimento ao aluno denominado Call Center, por meio do qual os estudantes podiam enviar suas questões aos professores virtuais.

Os titulares ministravam as disciplinas no estúdio de TV da própria universidade, em canal fechado. As aulas eram transmitidas aos 62 municípios do Estado, que compunham 158 turmas em uma etapa do interior e 26 turmas em etapa para a capital, exclusivamente. A maior parte dos titulares pertencia à Universidade Federal do

3 Programa de Formação de Professores para o Magistério da Educação Básica (PROFORMAR). Tal curso foi ministrado para 20 mil professores no Estado do Amazonas. 
Amazonas. Eles elaboravam as DL (dinâmicas locais), atividades para aumentar o nível de compreensão dos estudantes sobre os assuntos estudados em cada um dos componentes curriculares do Curso. Abaixo uma ilustração dos dois professores: o presencial e o virtual.

Figura 1 - Professora assistente mediando presencialmente a aula da professora titular.

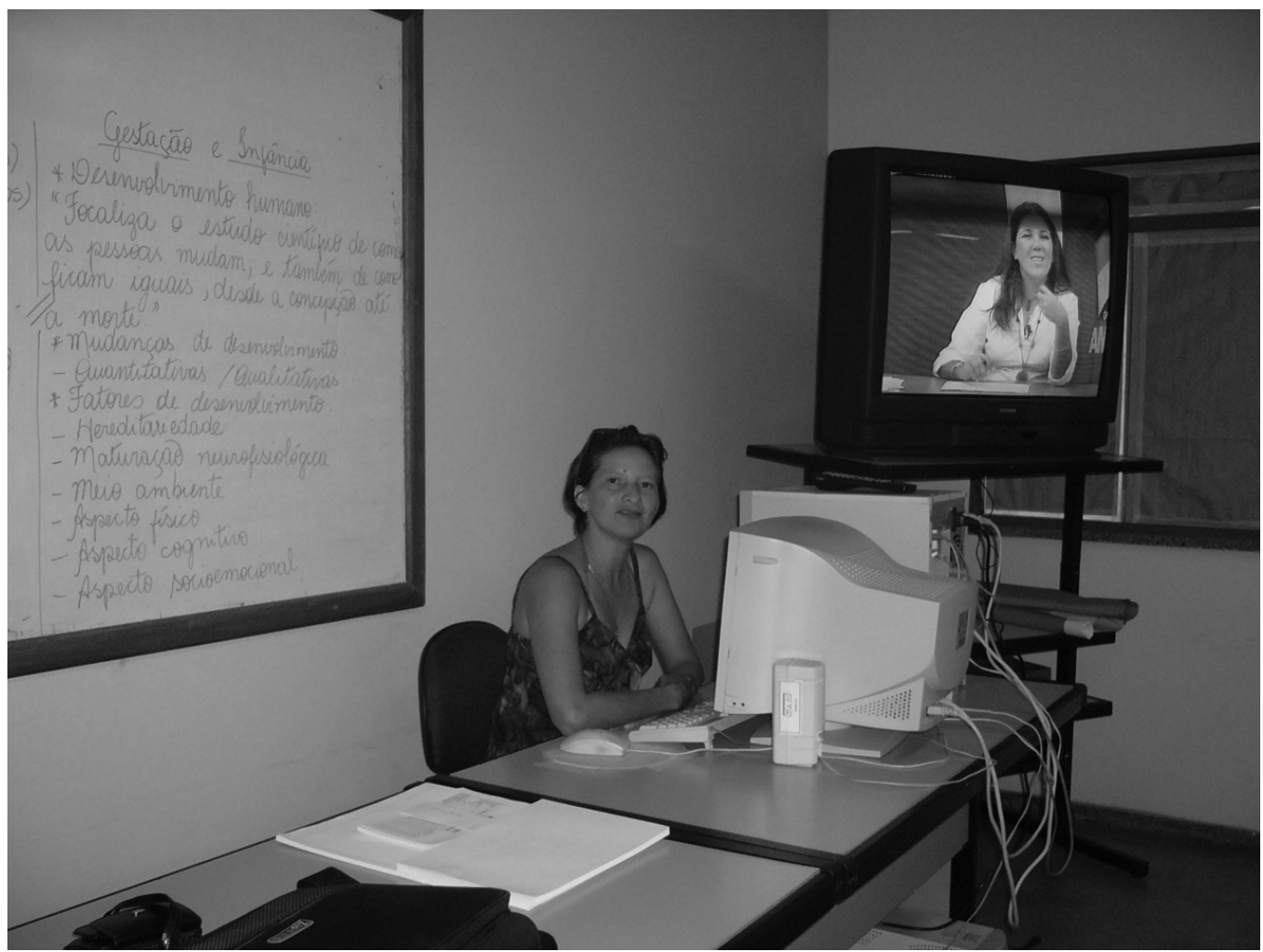

O pouco contato dos professores titulares com os estudantes, somente através do vídeo, não favorece o conhecimento das limitações e potencialidades da turma. Sendo os responsáveis pelos discursos pedagógicos, muitas vezes sem conhecer o ambiente ao qual os estudantes pertencem, esses professores elaboram suas estratégias de aprendizagem sem observar o estudante concreto. Essa dificuldade deve ser superada a partir da interação com o professor assistente, aumentando a necessidade de este professor atuar como um forte articulador das aprendizagens.
Os professores assistentes assumiam a turma em carácter presencial, realizavam as mediações necessárias entre alunos e estúdio, incentivavam os estudos, a realização das DL (dinâmicas locais), observavam a frequência e aplicavam as provas preparadas pelos titulares, que eram transmitidas pela TV. Deviam estabelecer a ponte entre o presencial e a distância, incentivavam a participação e os questionamentos dos educandos.

Por ser responsável pela parte presencial, o professor assistente convivia integralmente com o estudante, durante o período 
das aulas, pois cumpria uma jornada de trabalho, dentro de sala de aula, de mais de 40 horas semanais, o que facilitava conhecer e identificar os pontos fortes e as limitações da turma. Todavia, muitos desses professores assistentes sentiam dificuldades em auxiliar as discussões dos professores titulares, tendo em vista que alguns não possuíam formação pedagógica compatível com as disciplinas do curso, ou por inexperiência no projeto, por desconhecimento dos pressupostos teóricos que orientavam as disciplinas ministradas, ou até mesmo por não assumirem a responsabildade que exigia um projeto dessa natureza.

Figura 2 - Sala de aula convencional, professora à direita, alunos à esquerda e ao fundo.

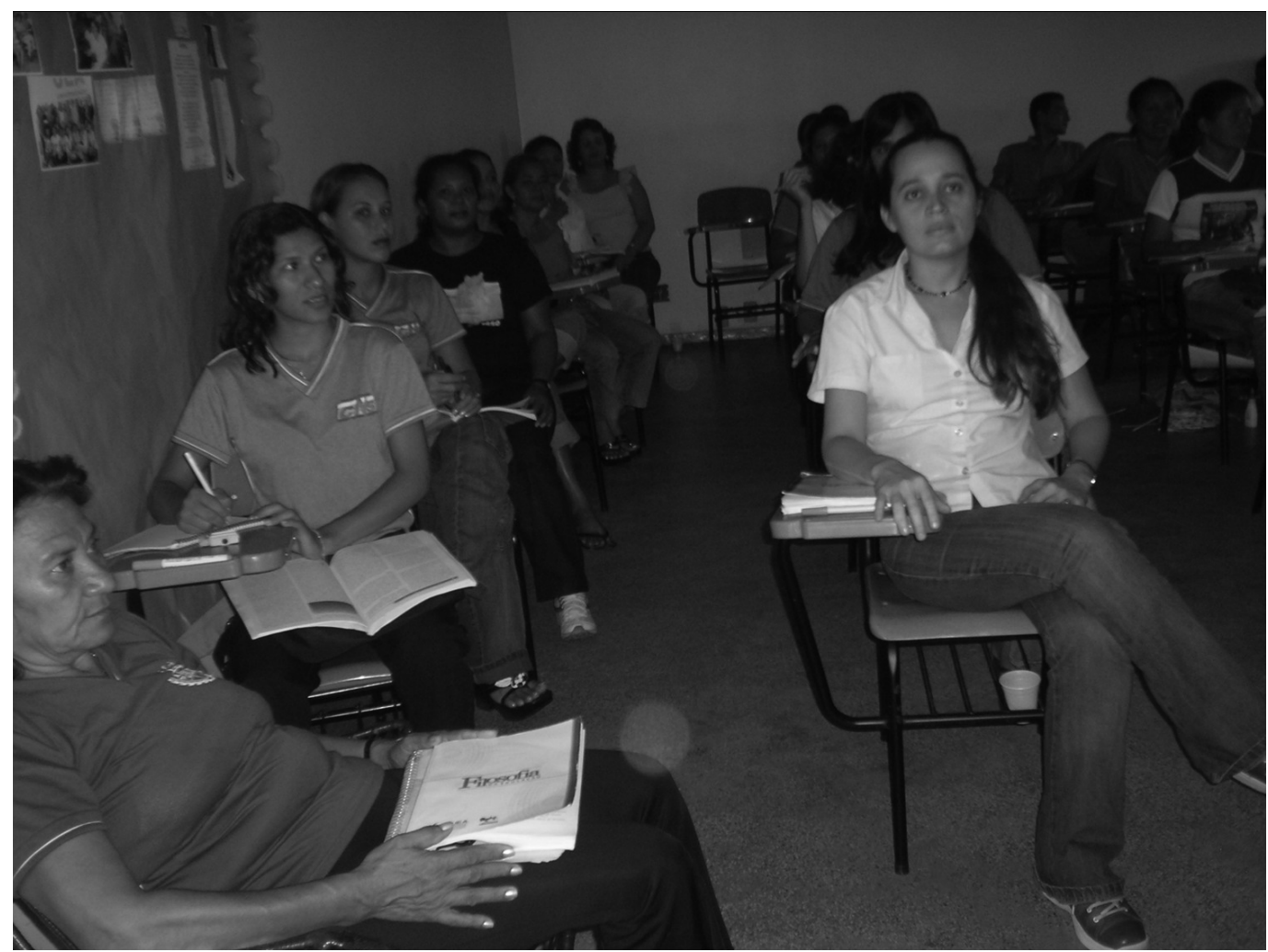

Entedemos que em programas de formação de professores, em especial no PROFORMAR, o pouco contato dos formadores virtuais (titulares) com os estudantes e as dificuldades dos que atuavam em caráter presencial, mas que não dominavam os pressupostos teóricos do curso, sempre representaram um problema ao bom desenvolvimento da ação educativa que se pretendia estabelecer naquele curso de formação.
Surgiu, assim, a necessidade de qualificar não só o estudante-professor, mas também os formadores desses alunos a partir do que lhes faltava. No caso dos titulares, levá-los a discutir sobre quem eram seus educandos, quais as dificuldades que apresentavam para desenvolver as atividades pedagógicas propostas, quais os discursos que lhes despertavam o interesse e os motivavam para a aprendizagem. Para os assistentes, 
a identificação de modelos e estratégias que além de favorecer a sua ação dentro de sala de aula, promoviam a compreensão das suas dinâmicas.

Uma formação com esse caráter só seria possível de acontecer se fosse capaz de envolver os sujeitos formadores num mesmo processo educativo, estabelecendo a troca de experiências e de conhecimentos e favorecendo a reflexão-ação-reflexão dos professores responsáveis pelo desenvolvimento do ato educativo. Entretanto, em virtude de uma vida corrida e muitas vezes sacrificada, a maioria desses formadores não conseguia encontrar um momento para participar de cursos de atualização. Em algumas situações a tripla jornada de trabalho não favorecia o encontro e desestimulava a formação continua. ram:

Desse modo, os objetivos do curso fo-

- Criar uma comunidade de aprendizagem na web para formar os formadores de professores do Curso Normal Superior da modalidade PROFORMAR.

- Avaliar a motivação dos formadores de professores e a qualidade de suas interações, capacidade de partilha e construção de significados, durante o curso on-line.

- Identificar os possíveis obstáculos à criação de Comunidade de Aprendizagem online no Amazonas.

\section{O e-learning na formação de professores no Amazonas}

Ao criarmos a comunidade de aprendizagem on-line no PROFORMAR - para atender à necessidade de preparar os formadores de professores do Curso Normal Superior - tínhamos uma intenção clara: favorecer a troca de experiências entre os diferentes sujeitos responsáveis pelo desenvolvimento das aulas e do processo pedagógico como um todo; observar suas disponibilidades diante do encontro a partir dos recursos tecnológicos; verificar como reagiriam em fazer parte de um ambiente virtual de aprendizagem; e identificar os possíveis obstáculos.

A moodle foi a plataforma escolhida para o desenvolvimento da comunidade, um software que pode ser facilmente encontrado na Internet. É uma ferramenta gratuita que permite a criação de cursos sob os mais diferentes modelos pedagógicos, tanto os de carácter mais tradicionais, centrados na transmissão de conteúdos, quanto os que potencializam processos de produção colaborativa de conhecimentos. No ambiente moodle é possível criar fóruns de discussão, chats, enviar tarefas, compartilhar blogs, e acessar arquivos de áudio e imagens.

A comunidade foi estruturada em torno de três disciplinas especificas do Curso Normal Superior - Método de Pesquisa, Didática, Avaliação Educacional - e de um artigo voltado ao repensar das práticas pedagógicas e à função do docente em vista ao desenvolvimento de culturas colaborativas na escola. Cada disciplina possuiu um fórum, espaço pensado para dar suporte aos estudos de textos, permitindo que os alunos-professores pudessem trocar entre si e com os seus professores as dúvidas e os aspectos relevantes do conteúdo estudado. Entretanto, cedo percebemos as limitações desse modo de organizar as situações de aprendizagem on-line.

Logo no primeiro momento, ainda presencial, foram convidados a participar da experiência dezenove professores assistentes, cinco deles residentes no interior e 
quatro titulares; esses últimos seriam os responsáveis pelo desenvolvimento do curso, pela promoção das interações em torno dos temas escolhidos. O próprio estudante deveria inscrever-se no ambiente, preenchendo formulário on-line. Embora todos tivessem declarado possuir habilidade com a máquina, observamos que a maioria não dominava nem mesmo as operações mais básicas, como ligar e desligar o computador. Assim, nós mesmos tivemos que realizar as inscrições.

Dos quatro professores titulares, doutores em educação, apenas dois possuíam experiência com e-learning; os outros dois, apesar de reconhecidamente competentes em suas áreas de atuação, dominavam pouco os recursos do computador: apenas os aplicativos básicos, mesmo assim, com uma certa resistência. Na verdade, nenhum deles se identificava com essa modalidade de ensino, entretanto estavam curiosos e se disponibilizaram atenciosamente a desenvolver a pesquisa.

Desde o principio, tivemos problemas gravíssimos com a conectividade, tanto na universidade como fora dela. Os alunos-professores e os formadores, para conseguirem acessar e interagir no ambiente, em virtude de um sistema de internet precário, moroso, despendiam um tempo excessivamente longo, que provocava a desmotivação. Em alguns locais do interior do Estado, o acesso à rede chegava a demorar mais de 30 minutos para estar disponível ao usuário. Assim, nos caso dos formadores, se já não se identificavam com a modalidade de ensino on-line, com os problemas operacionais da rede, a antipatia pelo processo agravou-se.

O curso iniciou seguindo um modelo mais conservador, a partir de um estudo dirigido sobre Método Científico e um artigo sobre a função do professor hoje e a importância das culturas colaborativas na escola. Os alunos deveriam ler os textos, apresentados pelos professores, destacar os aspectos mais importantes, preparar uma síntese e enviá-la pelo espaço tarefa da disciplina, respeitando as datas de entrega.

Na disciplina de Didática, substituímos o estudo de texto no formato Word e decidimos trabalhar os conceitos de ensino e aprendizagem mediante a apresentação de slides, preparados no PoWerPoint, em que imagens de gibis mostravam cenas da escola. Também foi disponibilizado um texto de apoio sobre a questão. Em seguida, os alunos - a partir de suas experiências pessoais, na condição de professores, e das cenas apresentadas pelos gibis - deveriam definir primeiro individualmente, depois em grupo: o que é ensino e aprendizagem?

Embora cada disciplina possuísse um fórum para apoiar os estudos e favorecer a interação, os alunos-professores interagiam acanhadamente nos fóruns, não conseguiam cumprir com os prazos de entrega das atividades, deixando-nos seriamente preocupados. Apesar de o ambiente contar com uma variedade de recursos para motivar os alunos, como charges e filmes, logo percebemos que essa metodologia não estava favorecendo a participação. Sem saber, exatamente, o porquê da baixa interatividade, nos questionávamos com frequência sobre quais poderiam ser as melhores estratégias a serem utilizadas para aumentar a participação.

No entanto, observamos também que o fórum denominado bate-papo, destinado a estabelecer uma conversa mais informal, livre, não sofria do mesmo problema dos demais. Nele as interações eram significativas; textos poesias, slides com mensagens e fotos eram compartilhados com frequência. Atribuímos a participação intensa nesse espaço a dois fatores. O primeiro fator era a descontração: o estudante conversava com liberdade, sem preocupar-se com a formulação das 
questões, se estavam de acordo ou não com os textos estudados. Era como se eles se encontrassem aleatoriamente fora do horário das aulas e conversassem, informalmente, com um amigo. $\mathrm{O}$ outro fator era a possibilidade de responder as questões na página do próprio fórum: o aluno lia as questões e as respondia no mesmo ambiente.

As imagens da região, compartilhadas pelos estudantes no fórum, promoviam o diálogo entre eles, colaborando para a formação de vínculos de amizade, como podemos observar pelo comentário da aluna-professora Sebastiana (2006): “Veja bem Claudete, o que você faz ao exibir este entardecer do careiro, me faz transbordar de saudades de um outro careiro, o castanho, quando lá estive a saborear tão belo momento. Um abraço da baby.”

Figura 3 - Careiro da Várzea. Fotografada e disponibilizada no fórum, pela aluna Maria Claudete.

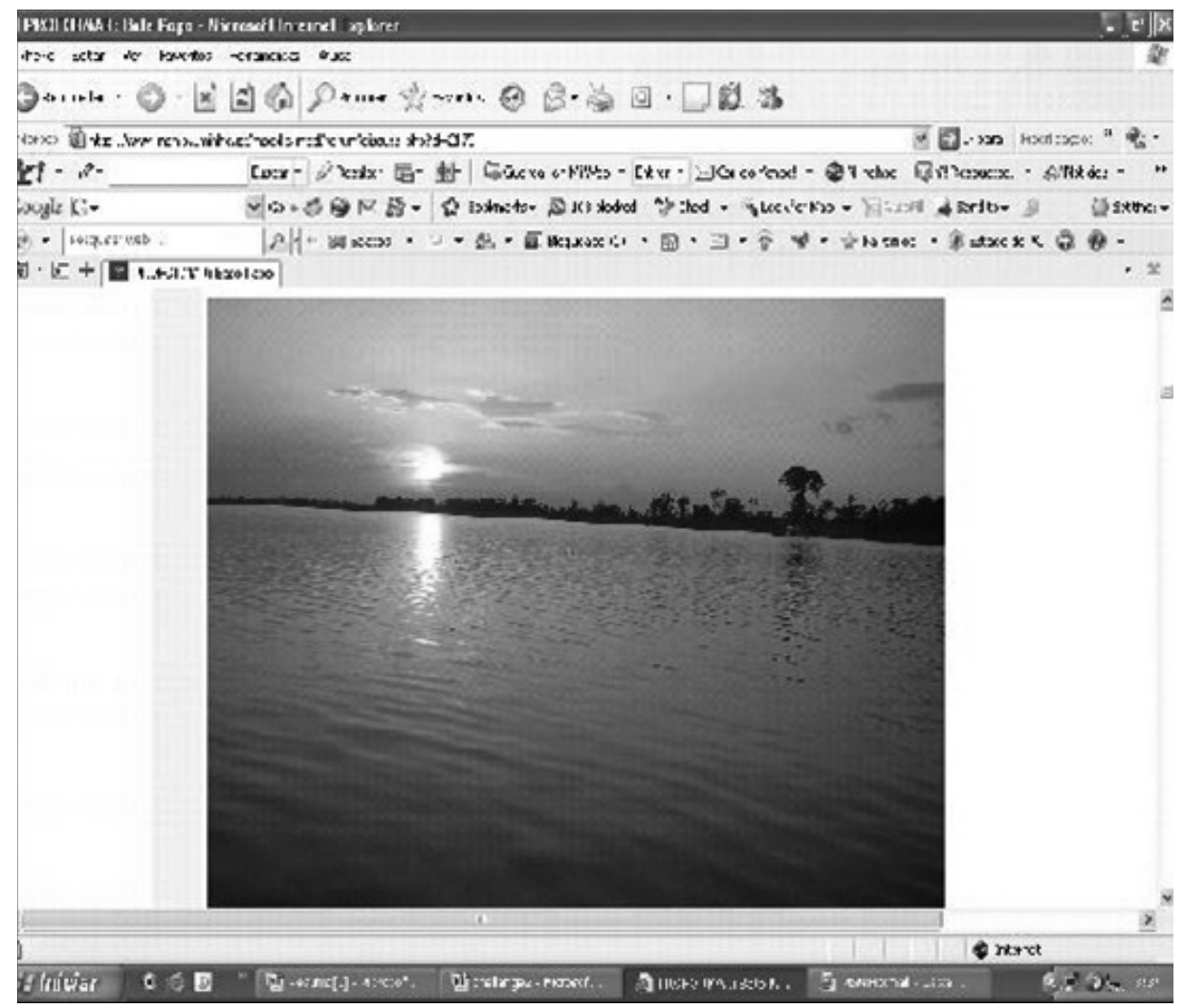

A partir de então passamos a desenvolver as atividades das disciplinas direto no ambiente on-line. Na disciplina de Avaliação Educacional, discutimos o problema do fracasso escolar utilizando-nos de um estudo de caso, o qual foi apresentado em forma de questão na própria página do fórum em que os estudantes deveriam tentar resolver um problema relativo à reprovação sistemática no Ensino Fundamental. Houve uma relativa melhora na interação, embora ainda assim os estudantes demorassem muito a responder às questões. Um exemplo da dificuldade de acessar a rede pode ser observada a partir da 
fala da aluna Marlucia Dantas no fórum de bate-papo:

Carol, ontem devido a chuva, tivemos problemas com o provedor, por isso atrasei a tarefa. Consegui acessar às 18:00 horas, e quando tentava enviar o arquivo com a tarefa do professor Walmir (formulação do problema), tivemos uma dificuldade local e desconectou, só conseguindo acessar novamente às 22:00 horas , ficando registrado, devido ao horário verão, a data: 15.11.06. Fiquei super triste, pois gostaria de cumprir fielmente o calendário de atividades, mas não foi possível, a velocidade da Internet está a passos de tartaruga.

Entretanto, essa demora em responder às tarefas, em interagir nos fóruns acompanhou os alunos do inicio ao fim do curso, havendo momentos em que, francamente, acreditávamos que haviam desistido, apesar de nossa preocupação constante em disponibilizar na plataforma links interessantes sobre escola, educação, meio ambiente, filmes, figuras, piadas, bibliotecas e museus internacionais. Dos 19 alunos-professores registrados no ambiente, somente dez conseguiram cumprir todas as etapas da formação, enviaram as atividades solicitadas e colaboraram com o desenvolvimento da comunidade de aprendizagem. Destes, três nunca acessaram, dois desistiram nas primeiras disciplinas e quatro na última.

Estávamos desapontados. Mesmo com todos os esforços possíveis para criar uma comunidade de aprendizagem on-line para atender aos professores do PROFORMAR, tínhamos a sensação de que o processo não atingia a velocidade e o envolvimento que esperávamos dos sujeitos. O que poderia ter acontecido?

A julgar pelas manifestações favoráveis que os alunos-professores expressavam na comunidade de aprendizagem, pelas suas falas entusiasmadas em relação ao ambiente criado, não nos pareceu que o problema fosse o formato do curso. Ieda Nicácio, no Fórum de Bate-papo, comenta: "Estou vivendo uma maravilhosa experiência, pois alem de romper a timidez com a internet estou podendo conhecer pessoas diferentes das que estou acostumada...”. Em seguida, no mesmo fórum, a professora Joristela de Souza Queiroz continua:

Saiba que estou muito contente em fazer parte desta comunidade, pois discutir $e$ repensar a educação com vistas na projeção de uma melhoria na formação do "homem" é um grande começo para a a construção de uma sociedade mais justa, plural e igualitária.

A terceira etapa da experiência nos esclareceu a questão, deixou-nos menos preocupados quanto à eficácia do processo estabelecido, embora tenha nos trazido outras preocupações. Em janeiro de 2006, a fim de observar os resultados da experiência, arrumamos nossas malas e nos dirigimos ao interior do Estado. Visitamos três professores assistentes que haviam concluído todo o processo na comunidade de aprendizagem na Web e que na ocasião de nossa visita estavam desenvolvendo as aulas mediadas pela tecnologia. Por uma questão de tempo e poucos recursos disponíveis para empreender viagens a municípios mais distantes na região, fomos aos mais próximos de Manaus.

Assim, durante um mês, quatro dias em cada município em que estivemos (Iranduba, Presidente Figueredo, Beruri), observamos que as professoras assistentes conduziam as aulas com segurança. Em alguns momentos, os professores titulares, na TV, abordaram as questões discutidas na comunidade de aprendizagem on-line: no caso de Didática, as percepções de ensino e aprendizagem; 
em Avaliação Educacional, o problema do fracasso escolar; e, em Método Cientifico, o desenvolvimento da ciência numa perspectiva histórica. Em cada um desses momentos as professoras assistentes recorreram aos conhecimentos adquiridos no ambiente on-line e demonstraram domínio do assunto.

Esse momento foi de fundamental importância para nós, pois ao sermos hospedados por nossos alunos-professores em suas próprias casas, descobrimos que muitos deles não possuíam computadores. A maioria, para ter acesso à Internet, ou pagava o que chamamos de Lan Hause, um cyber-café, ou recorria a funcionários da prefeitura e, como um favor, pedia para utilizar o sistema do órgão público. Ainda assim, na maioria das vezes, com uma conectividade precária. Logo, ficaram claros para nós os motivos da morosidade das respostas e da baixa interação na Comunidade.

Em nossa experiência profissional no interior do Estado do Amazonas, independentemente de estarmos ou não desenvolvendo pesquisa, ou simplesmente dando aulas, tivemos a oportunidade de vivenciar o isolamento da região.

No alto Amazonas, já chegamos a encontrar municípios completamente incomunicáveis. Para ilustrar o que dizemos, em 2006 tivemos que empreender uma viagem a Jutaí. O percurso foi feito em duas etapas: primeiro, pegamos um avião até Fonte Boa, cuja duração do voo é de, aproximadamente, uma hora e meia; em seguida, é necessário continuar o trajeto pelo rio. Havia apenas duas alternativas: ou pegávamos uma voadeira (lancha) e percorríamos o trajeto em duas horas e meia, ou embarcávamos em um recreio (barco regional) e realizávamos o mesmo trajeto em seis horas. Tivemos sorte e fomos convidados a embarcar com o prefeito de Jutaí, que havia ido a Fonte Boa telefonar ao palácio do governo, pois a cidade, naquela altura, estava há duas semanas totalmente incomunicável. Seja no alto ou no baixo Amazonas, a maioria das escolas dos municípios não possui sequer laboratório de informática. Algumas delas, embora contempladas, mantêm as máquinas trancadas, ou subutilizadas; uma boa parte dos professores não tem formação em informática básica, nem possui computadores em casa. Obviamente, a Internet é ainda um serviço que atende a poucos, ainda assim precariamente. Mesmo as cidades consideradas mais avançadas, com melhor índice econômico, apresentam problemas em seus sistemas de comunicação.

Com o objetivo de ampliar as oportunidades de acesso à rede mundial de informação - Internet, o Governo Federal desenvolve programas de inclusão digital. A Secretaria de Educação do Estado do Amazonas, através do GESAC, tem gerenciado a implantação de pontos de conectividade nas escolas do interior e até mesmo na Capital, sensibilizando as comunidades locais e seus lideres para a importância e as vantagens do uso da tecnologia de rede. No entanto, esse trabalho precisa estar articulado a projetos de formação com forte responsabilidade social, que colaborem para o crescimento das pessoas beneficiadas pelos serviços.

Ao mesmo tempo que nos revelou as dificuldades do e-learning no Amazonas, a experiência com os formadores do PROFORMAR nos fez perceber a necessidade de investimentos sérios na preparação de professores que poderão implementar uma educação a distância de qualidade a partir da Web, além de ter indicado as fragilidades dos sistemas de Internet na região e a precária infraestrutura de grande parte das escolas amazonenses. 


\section{Considerações finais}

Apesar da precariedade do sistema de Internet em todo o Estado do Amazonas, que dificultou o pleno desenvolvimento do curso, e da pouca habilidade do aluno-professor na exploração dos recursos tecnológicos, em especial o computador, consideramos que a experiência foi relevante, uma vez que foi possível perceber as dificuldades que devem ser superadas no desenvolvimento da Educação a Distância a partir da modalidade e-learning.

É preciso vencer os preconceitos e superar os condicionantes estruturais que têm impedido o uso dos recursos tecnológicos em grande parte das escolas amazonenses, como a falta ou a precariedade de laboratórios equipados com computadores e o sistema de banda larga que dá acesso a Internet, tanto na capital, Manaus, como no interior de todo Estado.

Embora a democratização do acesso à tecnologia seja um dever do Estado, é necessário garantir o uso inteligente da Internet. Isso pressupõe a formação de pessoal qualificado para atuar junto às escolas e às comunidades, de modo geral, preparando-as para o desenvolvimento de uma consciência coletiva que favoreça a formação de valores e princípios éticos capazes de contribuir para o estabelecimento de uma sociedade mais justa e socialmente responsável.

Desse modo, é importante investir na formação de formadores em tecnologia educativa, uma vez que serão eles os sujeitos responsáveis pela inclusão digital nas escolas. Mas essa formação deve se opor ao individualismo e estabelecer no próprio ato formativo os princípios da cooperação e a predisposição para a partilha. Nesse sentido, a Web, com seu enorme potencial de reunir e favorecer as interações entre as pessoas, representa um instrumento a favor das aprendizagens e deve ser considerada com maior interesse pelas escolas.

\section{Referências}

BERGSON, H. O pensamento e o movente. Sao Paulo: Martins Fontes, 2006.

CARVALHO, R. G. G. Cultura global e contextos locais: a escola como instituição possuidora de cultura própria. Disponível em: <http://www.rieoei.org/ deloslectores/1434GilGomes.pdf>. Acesso em: 20 mar. 2007.

CONTRERAS, D. J. A autonomia da classe docente. Portugal: Porto Editora, 2003.

DIAS, A. A. S; GOMES, M. J. E-learning para e-formadores. Guimarães: Portugal, Tecminho, 2004.

DIAS, P. Comunidades de aprendizagem na Web. Inovação. Portugal: Universidade do Minho, 2001. 14(3), 27-44.

GHEDIN, E.; FRANCO, M. A. S. Questões de método da pesquisa em educação. 2. ed. Sao Paulo: Cortez, 2011.

. Professor reflexivo: da alienação da técnica à autonomia da crítica. In: PIMENTA, S.G.; GHEDIN, E. Professor reflexivo no Brasil: gênese e crítica de um conceito. 2 . ed. São Paulo: Cortez, 2002.

GONÇALVES, C. B. O desenvolvimento das comunidades de aprendizagem online: um estudo de caso na formação de Professores no Amazonas (2010). Disponível em http://repositorium.sdum.uminho. pt/bitstream/1822/12230/1/Carolina $\% 20$ Brand\%C3\%A3o\%20Gon\%C3\%A7alves.pdf.

HARGREAVES, A. $O$ ensino na sociedade do conhecimento: educação na era da insegurança. Porto Alegre: ArtMed, 2004. 
MAGDALENA, B. C.; COSTA, I.E.T. Internet em sala de aula: com a palavra, os professores. Porto Alegre: Artmed, 2003.

MORIN. E. A cabeça bem feita: repensar a reforma, reformar o pensamento. 2.ed. Rio de Janeiro: Bertrand Brasil, 2000.

PIAGET, J. O nascimento da inteligência da criança. São Paulo: Editora Crítica, 1986.

Epistemologia genética. 3. ed. São Paulo: Martins Fontes, 2007.

A formação do símbolo na criança: imitação, jogo, imagem e representação. 4. ed. Rio de Janeiro: LTC, 2010.

Seis estudos de Piaget. ed. Rio de Janeiro: Forense Universitária, 2011.

SACRISTÁN, J. G.; GOMES A.I.P. Compreender e transformar o ensino. 4. ed. Porto Alegre: ArtMed, 1998.

SALMON, G. E-atividades el factor clave para una formación en línea activa. Espanha, Barcelona: Editora UOC, 2004.

TARDIF, M.; LESSARD, C. $O$ trabalho docente: elementos para uma teoria da docência como profissão de interações humanas. Petrópolis, RJ: Vozes, 2005.

VIGOTSKY, L. A formação social da mente. 6. ed. São Paulo: Martins Fontes, 1998.

. Pensamento e linguagem. 2. ed.

São Paulo: Martins Fontes, 1998a. o desenvolvimento psicológico na infância. São Paulo: Martins Fontes, 1998b. - Linguagem, desenvolvimento e aprendizagem. São Paulo: Ícone, 2001.

Enviado em: 23/09/2009

Aceito em: 03/03/2011 